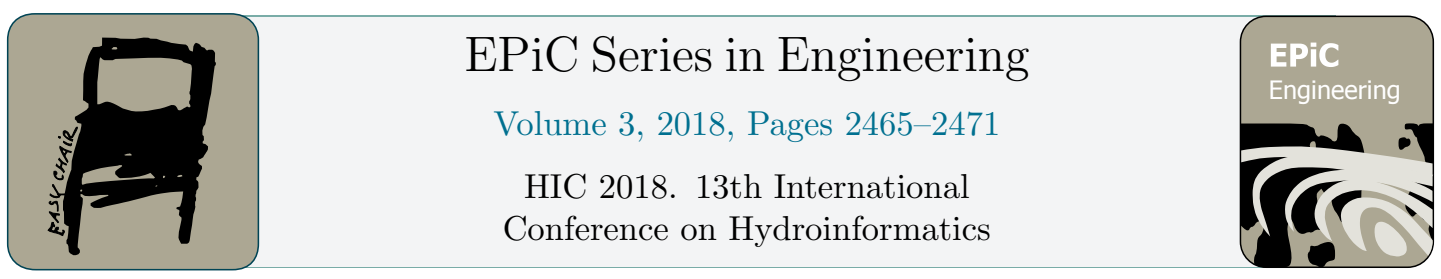

\title{
Assessment of Hydromorphological Characteristics in Sakarya Watershed, Turkey
}

\author{
Cansu Özcan ${ }^{1}$, Elçin Kentel ${ }^{2}$, Emre Alp ${ }^{1, *}$ \\ ${ }^{1}$ Department of Environmental Engineering, Middle East Technical University, \\ Üniversiteler Mah, Dumlupınar Blv. 06800 Çankaya-Ankara, Turkey \\ 2 Department of Civil Engineering, Water Resources Laboratory, Middle East \\ Technical University, Universiteler Mah. Dumlupınar Blv. 06800 Ankara, Turkey \\ *Corresponding author. Department of Environmental Engineering, Middle East \\ Technical University, Üniversiteler Mah, Dumlupinar Blv. 06800 Çankaya-Ankara, \\ Turkey,emrealp@metu.edu.tr,Tel.: +90 312210 5853; Fax: +90 3122102646
}

\begin{abstract}
Hydromorphology is one of the key components of ecological integrity of a waterbody according to European Union Water Framework Directive (WFD). Therefore, hydromorphological quality assessment plays a significant role in evaluating the status of aquatic life. The aim of this study is to assess hydromorphological characteristics of Sakarya Watershed where hydromorphological alteration and anthropogenic pressures are significant. Morphological conditions of the streams, river continuity and hydrological regime are evaluated. In this study, hydrological foundation of the assessment is established using a hydrologic model, Water Evaluation and Planning Model (WEAP). Moreover, Geographic Information System (GIS) and Remote Sensing (RS) tools in addition to field surveys are used in the spatial and temporal evaluation of the hydromorphological characteristics in the study area. It is believed that the outcomes of this study will aid decision makers to develop sustainable management alternatives to improve ecological integrity in Sakarya Watershed.
\end{abstract}

Keywords: Hydromorphological Assessment, Remote Sensing, Sakarya River Basin, Water Framework Directive, WEAP.

\section{Introduction}

Turkey, one of the countries in an accession period for European Union, is still preparing the river basin management plans consistent with the Water Framework Directive (WFD) and enacts its environmental regulations according to these plans. In the scope of WFD [1], Integrated Watershed Management (IWM) is the key concept 
for the basin management plans. The main environmental objective of the directive is that the management of the quality, quantity and structure of aquatic environments is required to achieve "good ecological and good chemical status" for all water bodies that can be natural, heavily modified or artificial [2]. Ecological status is composed of biological, hydromorphological and chemical - physicochemical quality components for rivers. As Benjankar et al. (2013) states, quantification of ecological condition of the river system is a critical component of IWM [8]. For that purpose, different elements and normative definitions of surface water bodies have been provided under the 3 ecological quality components in the directive. The aim of this study is to assess hydromorphological characteristics of Sakarya Watershed where hydromorphological alteration and anthropogenic pressures are significant. This study is a part of a comprehensive study titled 'Evaluation of Water, Energy and Food Nexus in Sakarya Watershed' supported by The Scientific and Technological Research Council of Turkey (TUBITAK).

Sakarya Watershed which is one of the 25 river basins in Turkey, encompasses $7 \%$ of Turkey's area. Drainage area of the basin is $58,160 \mathrm{~km}^{2}$ and total length of the main stem Sakarya River is $720 \mathrm{~km}$. The total population and the population density of the region are 7,588,968 cap and $130 \mathrm{cap} / \mathrm{km}^{2}$. Sakarya Watershed has an annual average precipitation of $479 \mathrm{~mm}$ and it is among 4 river basins in Turkey having annual precipitation less than $500 \mathrm{~mm}$. In the watershed, there are 6 sub-watersheds, Upper Sakarya, Ankara Creek, Porsuk Creek, Goksu-Karasu, Middle Sakarya and Lower Sakarya sub-watersheds [3]. Since urbanization, agriculture, industry and energy are the main sectors using water in the watershed, pre-assessment of the hydromorphological pressures and alterations in the region showed that major hydrological and morphological (e.g. seasonality changes, hydropeaking, reduced flow, continuum disruption,.etc.) alterations are present. The Sakarya Watershed and its sub-basins are depicted in Figure 1. 


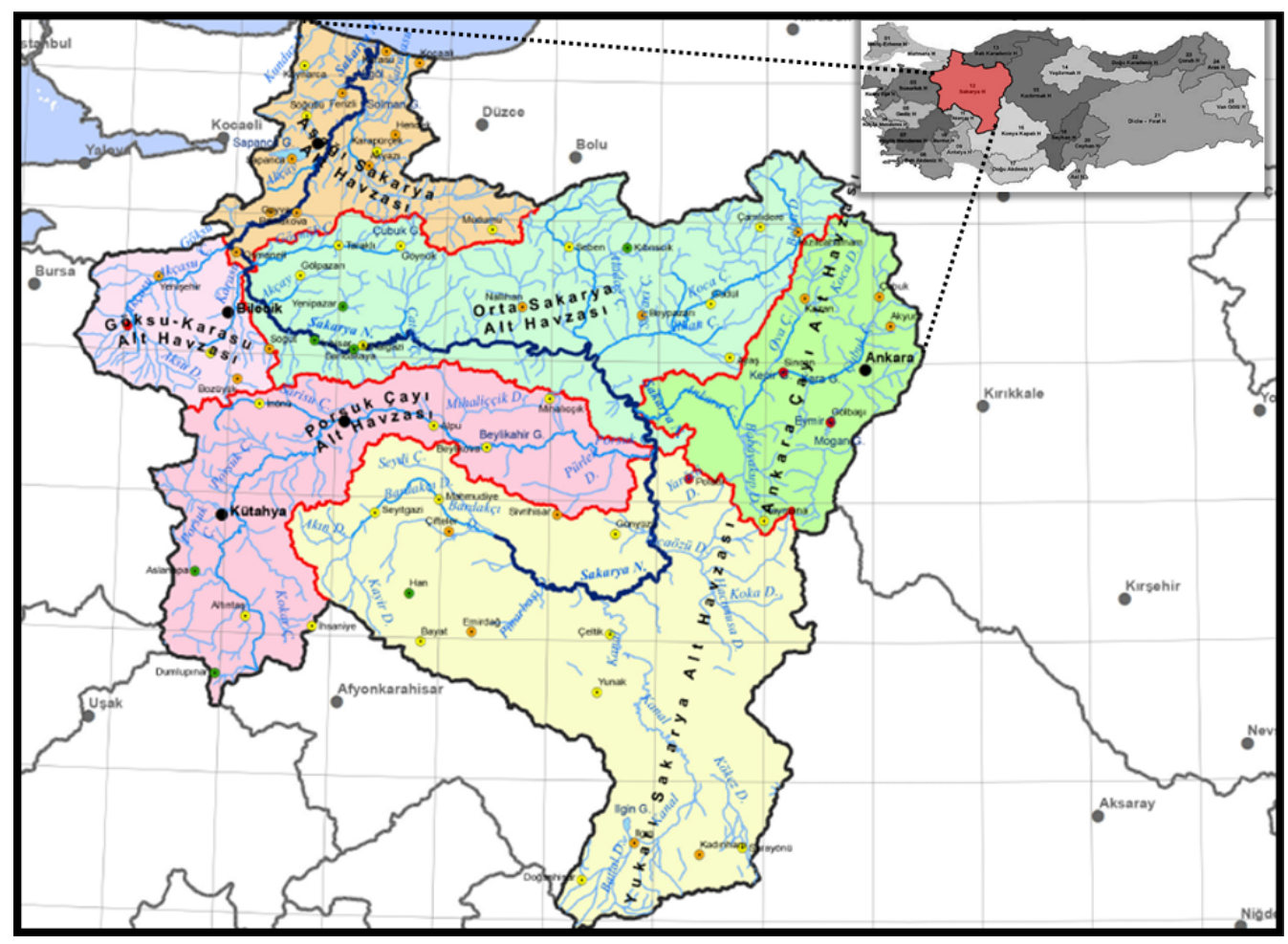

Figure 1 Map of Sakarya River Basin and Its Sub-basins [3]

\section{Material and Methods}

With the introduction of WFD, numerous hydromorphological assessment methods have been proposed. The methods vary in terms of their concepts, aims, spatial scales, data requirements and their applicability [4]. The literature about hydromorphological assessment methodologies has been reviewed and it is decided that the most appropriate method for Sakarya river basin will be implemented by combination of main steps of the assessments [5], [6], and [7].

This approach is mainly composed of following steps:

- General setting and segmentation in the scope of hierarchical framework

- Reference condition determination

- Determination of parameters and indicators defining pressures and alterations

The approach is represented in Figure 2 . 


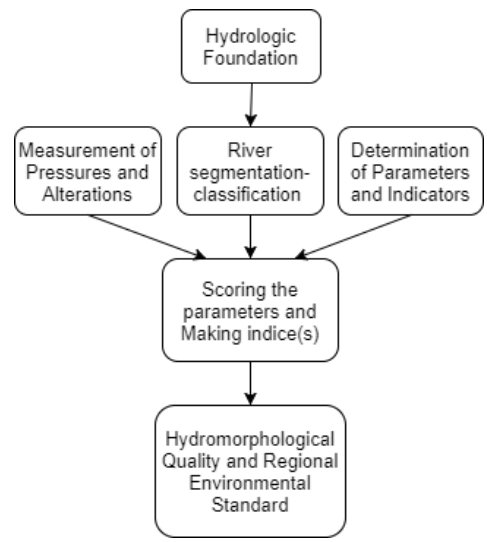

Figure 2 Hydromorphological Assessment Approach for Sakarya Watershed

Hydrologic foundation is developed by Water Evaluation and Planning (WEAP) model in this study. All hydraulic and hydrologic data will be obtained from this model that is built for each sub basin in the study area (see Figure 1).

Hydromorphological quality assessment requires a scoring system which consists of indicators and indices determined according to area-specific criteria and defined anthropogenic hydromorphological pressures and morphological alterations. The methodology for the analysis in this study follows a multi-phase protocol adapted to available data [8]. Initially, relevant indicators are determined, the class system is described with respect to reference condition and finally the level of pressure and alteration is evaluated for each indicator by assigning a score to each class of change. Assignment of scores will be carried out using different tools. They are field survey, database, expert knowledge and technological tools. Recently, the most commonly used and useful technological tools for these types of assessments are Geographic Information Systems and Remote Sensing. Also, survey sites and reference sites will be detected using both GIS and RS. High resolution satellite images of the sites will be interpreted to support field surveys at both temporal and spatial scales.

\section{Results - Discussion \& Conclusions}

Until now, some field surveys have been conducted to obtain flow regime profile of the Sakarya River. Average, maximum and minimum water velocity, average and maximum depth of water, flowrate, temperature, width and area of the river have been accurately measured at selected measurement points by using Acoustic Doppler Current Profiler. June and September have been chosen as measurement times because the flowrate is likely to be the highest in June and the lowest in September, where the results of the measurements are validating this statement. The highest flowrate has been observed at Tepetarla, Sakarya in June and its value is $216 \mathrm{~m}^{3} / \mathrm{s}$ while the lowest flowrate is $0,071 \mathrm{~m}^{3} / \mathrm{s}$ and observed at Göynük Creek, Bursa in September. The profile has been ploted by WinRiver-II software. 
Low-flow period of a river is fundamental importance to the ecological life and the field surveys should be carried out during these periods because the riverbed structure and substrate is visible [9] and suitable to make the measurements and observations for hydromorphological assessment and calculation of environmental flow needs. One of our field surveys has been conducted in September, 2017 when the flowrate of Sakarya River has its lowest level. According to the results of this survey Table 1 shows the ranges for 4 hydrological findings of Acoustic Doppler Current Profiler. The findings belong to 15 measurement points in the whole watershed.

Table 1 Results of Field Survey Conducted in September, 2017

\begin{tabular}{lc}
\hline Hydrological measurements & Range \\
\hline Average water velocity $(\mathrm{m} / \mathrm{s})$ & $0.04-1.28$ \\
Maximum depth of riverbed $(\mathrm{m})$ & $0.307-5.24$ \\
Flowrate $\left(\mathrm{m}^{3} / \mathrm{s}\right)$ & $0.071-47.7$ \\
Width of riverbed $(\mathrm{m})$ & $3.6-48.8$ \\
\hline
\end{tabular}

In December, 2017 while hydrological measurements have been carried out, a morphological pre-assessment for the selected measurement points has been conducted to assess morphological characteristics of the watershed. With the help of a detailed literature survey for hydromorphological field studies, some morphological criteria and parameters have been determined, such as slope of river banks, floodplain vegetation, substrate type of riverbed, stabilization, channel planform etc. After determination of these parameters and criteria, a field survey protocol has been developed to take notes about morphological characteristics. A protocol filled for $18^{\text {th }}$ point, which is added to measurement points after low-flow field survey, can be seen in Table 2.

Table 2 Results of morphological pre-assessment for $18^{\text {th }}$ point

\begin{tabular}{lc}
\hline Morphological parameter & Observation \\
\hline Slopes of river banks (left - right) & $20-45^{\circ}$ for left bank \\
& $20-45^{\circ}$ for right bank \\
Bank stabilization & Riprap bank stabilization \\
Floodplain vegetation & Native trees \\
& Tall herbs \\
Floodplain land use & Agriculture \\
Artificial bed structures & Not observed \\
\hline
\end{tabular}


In addition to field surveys, pre-assessment of hydromorphological pressures and alterations have been conducted from a comprehensive literature survey. Major pressures and alterations are:

- A large number of reservoirs and hydroelectric power plants for energy production in Middle Sakarya sub-watershed

- High amount of sediment transport and deposition to Lower Sakarya subwatershed due to quarry areas' activities and upstream flow regime

- Dams constructed for irrigation and flood control in Porsuk Creek and Ankara Creek sub-watersheds

- Overexploitation of groundwater resources and surface waters for irrigational purposes in Porsuk Creek, Ankara Creek and Higher Sakarya sub-watersheds

- Intensive urban development and industrial activities in Lower Sakarya, Ankara Creek and Porsuk Creek sub-watersheds

These pressures and alterations have different types of possible adverse effects on hydromorphological quality of the watershed. Reservoirs, dams and hydroelectric power plants constructed result in significant amount of reduction in downstream environmental flow, increase in salinity of groundwater resources and decrease in groundwater discharges to surface water bodies. Most importantly, longitudinal and lateral continuity of the river are significantly interrupted due to these structures. Flow fluctuation, hydropeaking, caused by the variability in water release from reservoirs disrupts the stability of river bed. High amount of sediment transport and deposition also causes low environmental flow, changing the river bed structures and adversely affecting the riparian habitats. Besides, water demand for agricultural activities is dominant in the Porsuk Creek, Ankara Creek and Upper Sakarya sub-watersheds and this leads to a considerable decrease in the amount of flow.

\section{Acknowledgements}

We would like to acknowledge funding by the Scientific and Technological Research Council of Turkey (TÜBİTAK) for the project entitled "Evaluation of Water, Energy and Food Nexus in Sakarya Watershed", Project number 116Y166. 


\section{Reference}

[1] EC (European Commission). (2000). DIRECTIVE 2000/60/EC OF THE EUROPEAN PARLIAMENT AND OF THE COUNCIL of 23 October 2000 establishing a framework for Community action in the field of water policy. Official Journal of the European Communities, L 269(September 2000), 1-93. http://doi.org/2004R0726 - v.7 of 05.06.2013

[2] EC (European Commission). (2007). WFD and Hydro-morphological pressures POLICY PAPER.

[3] MAM, T. (2013). Havza Koruma Eylem Planlarının Hazırlanması Projesi (Vol. 5118601). Gebze, Kocaeli.

[4] Rinaldi, M., Belletti, B., Bussettini, M., Comiti, F., Golfieri, B., Lastoria, B., ... Surian, N. (2017a). New tools for the hydromorphological assessment and monitoring of European streams. Journal of Environmental Management, 202(August), 363-378. https://doi.org/10.1016/j.jenvman.2016.11.036

[5] Poff, N. L., Richter, B. D., Arthington, A. H., Bunn, S. E., Naiman, R. J., Kendy, E., ... Warner, A. (2010). The ecological limits of hydrologic alteration (ELOHA): A new framework for developing regional environmental flow standards. Freshwater Biology, 55(1), 147-170. https://doi.org/10.1111/j.1365-2427.2009.02204.x

[6] Rinaldi, M., Belletti, B., Bussettini, M., Comiti, F., Golfieri, B., Lastoria, B., ... Surian, N. (2017b). New tools for the hydromorphological assessment and monitoring of European streams. Journal of Environmental Management, 202(November 2016), 363-378. https://doi.org/10.1016/j.jenvman.2016.11.036

[7] Ioana-Toroimac, G., Zaharia, L., \& Minea, G. (2015). Using pressure and alteration indicators to assess river morphological quality: Case study of the Prahova River (Romania). Water (Switzerland), 7(6), 2971-2989. https://doi.org/10.3390/w7062971

[8] Benjankar, R., Koenig, F., \& Tonina, D. (2013). Comparison of hydromorphological assessment methods: Application to the Boise River, USA. Journal of Hydrology, 492, 128-138. https://doi.org/10.1016/j.jhydrol.2013.03.017

[9] Morten, A., Pedersen, L., Ovesen, N. B., Friberg, N., Clausen, B., \& Grešková, A. (2004). Annex 1 Hydromorphological Assessment Protocol for the Slovak Republic. Rivers. 